\title{
Microwave assisted solvent free oxidation of hydrobenzoins, benzoins and alcohols with $\mathrm{NBS}-\mathrm{Al}_{2} \mathrm{O}_{3}$
}

\author{
Jitender M. Khurana* and Reema Arora \\ Department of Chemistry, Delhi University, Delhi-110007 \\ E-mail:jmkhurana@yahoo.co.in
}

\begin{abstract}
A simple and efficient protocol for microwave-assisted solvent-free oxidation of hydrobenzoins to benzoins or benzils, benzoins to benzils, and alcohols to the corresponding aldehydes or ketones, using $N$-bromosuccinimide - neutral alumina is reported.
\end{abstract}

Keywords: Oxidation, carbonyl compounds, diols, hydrobenzoins, microwave irradiation.

\section{Introduction}

Oxidation of alcohols to the carbonyl moiety can be achieved by an array of reagents. ${ }^{1}$ Recently other reagents e.g., cobalt(II) complexes, ${ }^{2} m$-iodosylbenzoic acid/ $\mathrm{RuCl}_{3}{ }^{3}{ }^{3} \mathrm{IBX} / n-\mathrm{Bu}_{4} \mathrm{~N}^{+} \mathrm{Br}^{-}$ $/ \mathrm{CH}_{2} \mathrm{Cl}_{2}-\mathrm{H}_{2} \mathrm{O},{ }^{4}$ DABCO/ $\mathrm{Br}_{2},{ }^{5}$ DMSO$/ \mathrm{N}_{2} \mathrm{H}_{4} \cdot \mathrm{H}_{2} \mathrm{O} / \mathrm{I}_{2} / \mathrm{H}_{2} \mathrm{O} / \mathrm{CH}_{3} \mathrm{CN},{ }^{6}$ have also been reported. Hydrobenzoins and benzoins have also been oxidized with $\mathrm{Bi}\left(\mathrm{NO}_{3}\right)-\mathrm{Cu}(\mathrm{OAc})_{2}{ }^{7}$ $\mathrm{RuCl}_{3} /$ Bromamine-T, $^{8}$ the Burgess reagent, ${ }^{9} \mathrm{NBS} / \mathrm{CCl}_{4} /$ pyridine, ${ }^{10}$ etc. Many of these reagents lack generality for oxidation of alcohols, benzoins and hydrobenzoins, besides being expensive, and giving low yields and undesirable side products. Microwave-assisted solvent-free chemical reactions on inorganic solid supports have drawn attention recently. ${ }^{11} \mathrm{NBS}$ is an economical and convenient oxidant and has been used in a variety of oxidation reactions. ${ }^{10,12} \mathrm{We}$ have investigated the oxidation of hydrobenzoins, benzoins and alcohols with $\mathrm{NBS}-\mathrm{Al}_{2} \mathrm{O}_{3}$ in solventfree conditions expedited by microwave irradiation.

\section{Results and Discussion}

We report herein a simple and efficient solvent-free protocol for the microwave- accelerated oxidation of hydrobenzoins, benzoins and alcohols with N-bromosuccinimide-neutral alumina. The reaction conditions were optimized by carrying out reactions of hydrobenzoin (1a) as a model substrate and changing the molar ratios of NBS and $\mathrm{Al}_{2} \mathrm{O}_{3}$ besides variable microwave 
irradiation. It was observed that hydrobenzoin (1a) could be selectively oxidized to give benzoin (99\%) when exposed to microwaves for $20 \mathrm{sec}$ or to give benzil (3a) in quantitative yields when exposed to microwaves for 2 min using a 1:2 molar ratio of 1a: NBS and a 1:3 w/w ratio of Ia: neutral $\mathrm{Al}_{2} \mathrm{O}_{3}$. Other hydrobenzoins, namely $p, p^{\prime}$-dichlorohydrobenzoin (1b) and $o, o^{\prime}-$ dichlorohydrobenzoin (1c) could also be oxidized selectively under these reaction conditions (Scheme 1).

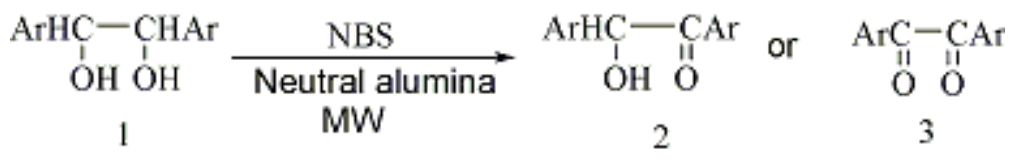

\section{Scheme 1}

Similarly, benzoins (2) could be quantitatively oxidized to the corresponding benzils (3) with NBS- $\mathrm{Al}_{2} \mathrm{O}_{3}$ when exposed to microwaves (Scheme 2). Both primary and secondary alcohols (4) underwent oxidation under these conditions to give the corresponding aldehydes or ketones (5) in quantitative yields (Scheme 3). Aldehydes obtained from primary alcohols did not undergo subsequent oxidation to give carboxylic acids, as has been confirmed by an independent reaction. The reactions were clean and rapid and atom economy was observed. The oxidations were complete in $20 \mathrm{sec}-6 \mathrm{~min}$ of microwave exposure. These results are summarized in Table 1.

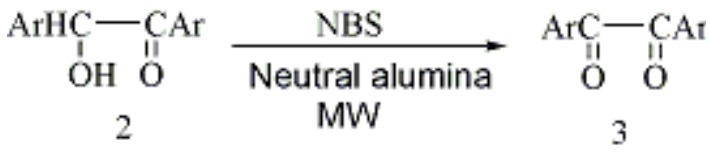

\section{Scheme 2}

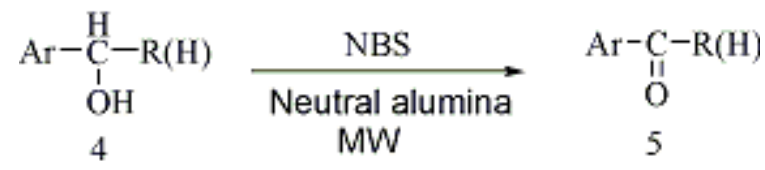

\section{Scheme 3}


Table 1. Microwave-assisted solvent free oxidation of hydrobenzoins, benzoins and alcohols using NBS-neutral alumina ${ }^{a}$

12)


17.

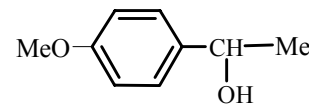

18.<smiles>OCc1ccc(Cl)cc1</smiles>

19.<smiles>OCc1cccc2ccccc12</smiles>

20.

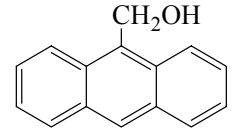

21.

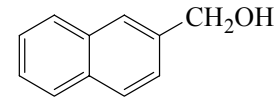

$20 \mathrm{sec}$

$1 \mathrm{~min}$

$30 \mathrm{sec}$<smiles>COc1ccc(C(=O)C(C)C)cc1</smiles><smiles>O=Cc1ccc(Cl)cc1</smiles><smiles>O=Cc1cccc2ccccc12</smiles>

$20 \mathrm{sec}$

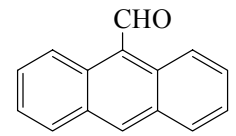

$50 \mathrm{sec}$
98

98

9

96

97

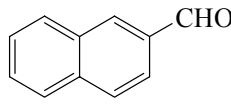

${ }^{\text {a }}$ Substrate: NBS, molar ratio $=1: 2$; substrate: neutral $\mathrm{Al}_{2} \mathrm{O}_{3}, \mathrm{w} / \mathrm{w}$ ratio $=1: 3$.

The oxidations were incomplete with lower molar ratios of substrate: NBS. The oxidations were also attempted on other inorganic solid supports such as silica gel, acidic alumina, and basic alumina, but in all these reactions, a mixture of products was obtained. Benzoins and alcohols did not undergo any oxidation with $\mathrm{N}$-chlorosuccinimide-alumina $\left(\mathrm{NCS}-\mathrm{Al}_{2} \mathrm{O}_{3}\right)$ instead of $\mathrm{NBS}-\mathrm{Al}_{2} \mathrm{O}_{3}$ under identical conditions.

\section{Conclusions}

We conclude that oxidation of hydrobenzoins, benzoins and alcohols to the corresponding benzoins, benzils, and carbonyl compounds can be achieved by NBS-neutral $\mathrm{Al}_{2} \mathrm{O}_{3}$ under microwave irradiation. Synergism of the microwave methodology and solvent-free conditions makes this oxidation an attractive and facile synthetic protocol for the oxidation of hydroxyl group.

\section{Experimental Section}

General Procedures. All the melting points were recorded on a Tropical Labequip apparatus and are uncorrected. IR spectra were recorded on Perkin-Elmer FT-IR SPECTRUM-2000. NMR spectra were recorded on a Hitachi FT-NMR model R-600 (60 MHz) with TMS as internal standard. The products were identified by co-TLC, m.p., mixed m.p. (wherever applicable), IR and NMR spectra.

General experimental procedure. In a typical procedure, the hydrobenzoin $(0.5 \mathrm{~g}, 2.33 \mathrm{mmol})$, $\mathrm{N}$-bromosuccinimide $(0.83 \mathrm{~g}, 4.67 \mathrm{mmol})$ and neutral $\mathrm{Al}_{2} \mathrm{O}_{3}(1.5 \mathrm{~g})$ were mixed thoroughly in a 
porcelain mortar for $10 \mathrm{~min}$. The resulting homogenized solid was transferred to a $50 \mathrm{~mL}$ beaker. The beaker was immersed in a neutral $\mathrm{Al}_{2} \mathrm{O}_{3}$ bath and irradiated with microwaves in a domestic microwave oven (using $100 \%$ of $900 \mathrm{~W}$ ) for $20 \mathrm{sec}$. The completion of the reaction was monitored by TLC using petroleum: ethyl acetate $(90: 10, \mathrm{v} / \mathrm{v})$ as eluent. The reaction mixture was cooled and extracted with ethyl acetate $(3 \times 10 \mathrm{~mL})$. The combined ethyl acetate extract was dried over anhydrous $\mathrm{MgSO}_{4}$, filtered, and evaporated on a Büchi evaporator. After drying under vacuum, a white solid was obtained which was identified as benzoin by m.p. and spectroscopic data.

\section{Acknowledgements}

RA is thankful to the University Grants Commission, New Delhi, INDIA for the award of JRF and SRF.

\section{References}

1. Larock, R. C. Comprehensive Organic Transformations, $2^{\text {nd }}$ Edn.; Wiley-VCH: New York, 1999.

2. Das, S.; Punniyamurthy, T. Tetrahedron Lett. 2003, 44, 6033.

3. Yusubov, M. S.; Gilmkhanova, M. P.; Zhdankin, V. V.; Kirschning, A. Synlett 2007, 563.

4. Kuhakarn, C. K.; Wittana, K.; Pohmakotr, M.; Reutrakul, V. Tetrahedron 2005, 61, 8995.

5. Heravi, M. M.; Derikvand, F.; Zadeh, M. G.; Neumuller, B. Tetrahedron Lett. 2005, 46, 6243.

6. Gogoi, P.; Sarmah, G. K.; Konwar, D. J. Org. Chem. 2004, 69, 5153.

7. Tymonko, S. A.; Nattier, B. A.; Mohan, R. S. Tetrahedron Lett. 1999, 40, 7657.

8. Jain, S. L.; Sharma, V. B.; Sain, B. Synth. Commun. 2005, 35, 465.

9. Jose, B.; Vishnu Unni, M. V.; Prathapan, S.; Vadakkan, J. J. Synth. Commun. 2002, 32, 2495.

10. Khurana, J. M.; Kandpal, B. M. Tetrahedron Lett. 2003, 44, 4909 and references cited therein.

11. (a) De La Hoz, A.; Diaz-Ortiz, A.; Moreno, A. Chem. Soc. Rev. 2005, 164. (b) Loupy, A. Microwaves in Organic Synthesis, Wiley-VCH, Weinheim, 2006.

12. (a) Barakat, M. Z.; Wahab, M. F.; Melsadr, M. J. Am. Chem. Soc. 1955, 77, 1670. (b) Baik, W.; Lee, H. J.; Kang, J. M.; Koo, S.; Kim, B. H. J. Org. Chem. 2000, 65, 108. 